IFAS Extension

\title{
Datos sobre la tiamina ${ }^{1}$
}

\author{
R. Elaine Turner y Wendy J. Dahl ${ }^{2}$
}

\section{¿Por qué necesitamos la tiamina?}

La tiamina es una de las vitaminas del grupo B. Es también llamada B1. Nosotros necesitamos tiamina para utilizar los carbohidratos que comemos. La tiamina ayuda a transformar los carbohidratos en energía para el cuerpo. El cuerpo también necesita tiamina para usar algunos de los aminoácidos que componen las proteínas.

\section{¿Qué pasa si no consumimos suficiente tiamina?}

La falta de tiamina causa la enfermedad beriberi. Las personas con beriberi tienen dificultad para estar de pie, caminar y controlar sus músculos. Esta enfermedad era común en los años 1800 en el Sureste de los países Asiáticos cuando las personas comenzaron a comer arroz blanco "pulido" en lugar de arroz integral. Al remover la cáscara del arroz, se elimina la mayor parte de la tiamina.

Es muy fácil obtener suficiente tiamina en la dieta, ya que esta se agrega en muchos granos procesados. Sin embargo, las personas que abusan de las bebidas alcohólicas o que poseen una dieta muy pobre pueden llegar a sufrir de una deficiencia de tiamina.

\section{¿Cuánta tiamina necesitamos?}

La tabla 1 muestra la cantidad recomendada diaria de tiamina.
Tabla 1. Ingesta diaria recomendada de tiamina en diferentes etapas de vida

\begin{tabular}{|l|c|}
\hline \multicolumn{1}{|c|}{ Etapa de vida } & Tiamina (mg/día) \\
\hline Hombres, edades 19+ & 1.2 \\
\hline Mujeres, edades 19+ & 1.1 \\
\hline Embarazo & 1.4 \\
\hline Lactancia & 1.4 \\
\hline mg = miligramos \\
\hline
\end{tabular}

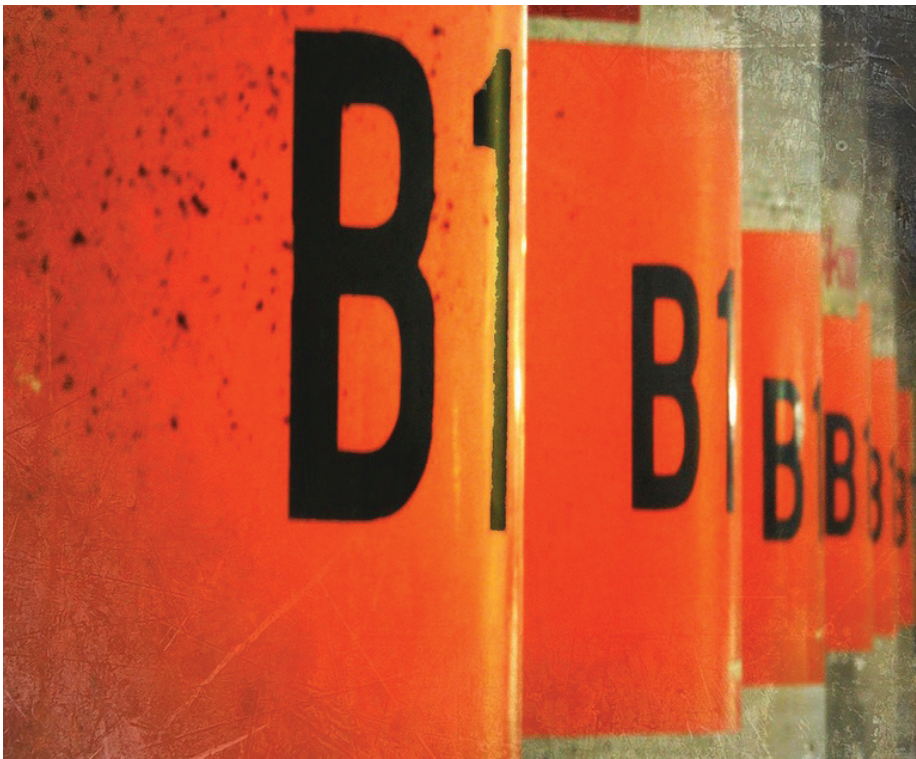

Figura 1. La tiamina se le llama también vitamina $B_{1}$ Credits: Tanakawho. CC BY-NC 2.0. http://flic.kr/p/912DXG

1. The English version of document is FCS8667/FY211 Facts About Thiamin. Este documento, FCS8667s, es uno de una serie de publicaciones del Departamento de Ciencias de la Familia, la Juventud y la Comunidad, Servicio de Extensión Cooperativa de la Florida, Instituto de Alimentos y Ciencias Agrícolas, Universidad de la Florida (UF/IFAS). Fecha de primera publicación noviembre de 2012. Visite EDIS en http://edis.ifas.ufl.edu/.

2. R. Elaine Turner, PhD, RD, profesora y decano asociada, College of Agricultural and Life Sciences; Wendy J. Dahl, PhD, RD, profesora asistente, Food Science and Human Nutrition Department; Universidad de la Florida; Gainesville, FL 32611. 


\section{¿Cómo podemos obtener suficiente tiamina?}

Las mejores fuentes de tiamina son los panes y cereales enriquecidos, fortificados o integrales. La tiamina es una de las cuatro vitaminas que se añaden a los productos enriquecidos hechos de grano. Busque la palabra "tiamina" en la lista de ingredientes de la etiqueta para ver si ha sido agregada.

Otras fuentes buenas de tiamina son el cerdo, las legumbres (frijoles y lentejas), jugo de naranja y las semillas de girasol. La tabla 2 muestra algunos alimentos y la cantidad de tiamina que contienen.

Tabla 2. Ejemplos de alimentos y los miligramos por porción de tiamina.

\begin{tabular}{|l|c|}
\hline \multicolumn{1}{|c|}{ Alimento } & $\begin{array}{c}\text { Tiamina (mg por } \\
\text { porción) }\end{array}$ \\
\hline Costillas de cerdo, cocidas, $3 \mathrm{oz}$ & 0.8 \\
\hline Cereal listo para comer, 1 taza & 0.4 \\
\hline Espagueti enriquecido, cocido, 1 taza & 0.4 \\
\hline Jugo de naranja, 1 taza & 0.3 \\
\hline Germen de trigo, $1 / 2$ oz & 0.3 \\
\hline Arroz, enriquecido, blanco, cocido, 1 taza & 0.3 \\
\hline Semillas de girasol, 2 oz & 0.2 \\
\hline Frijoles negros, cocidos, $1 / 2$ taza & 0.2 \\
\hline mg = miligramos & \\
\hline oz = onzas & \\
\hline
\end{tabular}

\section{¿Cómo deben ser preparados los alimentos para retener la tiamina?}

La tiamina puede perderse o destruirse en los alimentos cuando estos se cocinan, especialmente si se cocinan por un largo tiempo o se cocinan en grandes cantidades de agua. Sin embargo, debido a que muchas de las fuentes de tiamina no necesitan cocinarse, esto no es una preocupación importante.

\section{¿Qué pasa con los suplementos?}

La mayoría de las personas consumen gran cantidad de tiamina en sus dietas, por lo que los suplementos no son usualmente necesarios. La tiamina está incluida en la mayoría de los suplementos multivitamínicos.

Las investigaciones aún no han encontrado problemas con el consumo excesivo de tiamina proveniente de alimentos o multivitamínicos. Sin embargo, no hay necesidad de tomar suplementos que contengan más de $100 \%$ a $150 \%$ del valor diario de tiamina.

\section{¿Dónde puedo obtener más información?}

El agente de Ciencias de la Familia y del Consumidor (FCS) en la oficina de extensión de su condado puede tener más información escrita y clases de nutrición para que usted asista. Además, un dietista registrado (RD) puede proporcionarle información confiable.

Más información nutricional confiable se puede encontrar en los siguientes sitios del Internet:

- http://fycs.ifas.ufl.edu

- http://www.eatright.org

- http://www.nutrition.gov 